\title{
QUEEN'S
UNIVERSITY
BELFAST
}

\section{Parents' experiences of applied behaviour analysis (ABA)-based interventions for children diagnosed with autistic spectrum disorder}

Mcphilemy, C., \& Dillenburger, K. (2013). Parents' experiences of applied behaviour analysis (ABA)-based interventions for children diagnosed with autistic spectrum disorder. British Journal of Special Education, 4O(4), 154-161. https://doi.org/10.1111/1467-8578.12038

Published in:

British Journal of Special Education

Document Version:

Early version, also known as pre-print

Queen's University Belfast - Research Portal:

Link to publication record in Queen's University Belfast Research Portal

\begin{abstract}
Publisher rights
(C) 2013 NASEN.

This is the pre-peer reviewed version of the following article: McPhilemy, C. and Dillenburger, K. (2013), Parents' experiences of applied behaviour analysis (ABA)-based interventions for children diagnosed with autistic spectrum disorder. British Journal of Special Education, 40: 154-161, which has been published in final form at http://onlinelibrary. wiley.com/doi/10.1111/1467-8578.12038/abstract. This article may be used for non-commercial purposes in accordance with Wiley Terms and Conditions for Self-Archiving.

\section{General rights}

Copyright for the publications made accessible via the Queen's University Belfast Research Portal is retained by the author(s) and / or other copyright owners and it is a condition of accessing these publications that users recognise and abide by the legal requirements associated with these rights.
\end{abstract}

Take down policy

The Research Portal is Queen's institutional repository that provides access to Queen's research output. Every effort has been made to ensure that content in the Research Portal does not infringe any person's rights, or applicable UK laws. If you discover content in the

Research Portal that you believe breaches copyright or violates any law, please contact openaccess@qub.ac.uk. 
McPhilamy, C. \& Dillenburger, K. (2013). Parents' experiences of Applied Behaviour Analysis (ABA) -based interventions for children diagnosed with Autistic Spectrum Disorder in Europe. British Journal of Special Education, DOI: 10.1111/1467-8578.12038

Parents' experiences of applied behaviour analysis (ABA)-based interventions for children diagnosed with autistic spectrum disorder

Applied behaviour analysis (ABA)-based programmes are endorsed as the gold standard for treatment of children with autistic spectrum disorder (ASD) in most of North America. This is not the case in most of Europe, where instead a non-specified 'eclectic' approach is adopted. We explored the social validity of ABA-based interventions with 15 European families who had experience with home-based, mainly self-managed, ABAbased programmes for their own child/ren with ASD. The results of the study highlighted the overwhelmingly positive impact that ABA-based interventions had on their children in areas such as social skills, challenging behaviour, communication, gross and fine motor skills, concentration, interaction, independence, overall quality of life and, most importantly, a feeling of hope for the future. Implications for European policy on ASD are discussed.

Key words: autism, applied behaviour analysis, parent, evidence-based practice.

There is significant empirical evidence that early and intensive behaviour interventions based on behaviour analysis result in noticeable and lasting functional improvements for children with autism (Baer, Wolf \& Risley, 1968; Eikeseth, Smith, Jahr \& Eldevik, 2002; Howard, Sparkman, Cohen, Green \& Stanislaw, 2005; Lovaas, 1987; Matson, Benavidez, Stabinsky Compton, Paclawskyj \& Baglio, 1996; National Autism Center, 2009; Sallows \& Graupner, 
2005; Weiss, 1999; Wolf, Risely \& Mees, 1964). Therefore, ABA-based interventions for ASD are heavily endorsed in North America; however this is not the case in Europe where an unspecified broad-brush, 'one fits all’ eclectic approach is promoted widely (Dillenburger, 2011; McConkey, Kelly \& Cassidy, 2007; Ruane, 2009; Task Group on Autism, 2002). Parents who choose to avail themselves of ABA-based interventions for their children are largely left to their own devices and have expressed frustration about the hostility towards and misrepresentation of the science of behaviour analysis (Chiesa, 2005; Keenan, Dillenburger, Moderato, \& Röttgers, 2010).

The research reported here shows evidence of the social validity of home-based ABA programmes and shows a significant difference between parental understanding and demand for evidence-based interventions and the lack of health, social care and education professionals' accurate knowledge of ABA.

\section{Method}

\section{Ethics}

The research was conducted within Queens University Belfast (QUB) Research Governance Framework and approved by QUB School of Education Research Ethics Committee.

\section{Participants}

Fifteen families participated in the study; 12 of these families resided in Northern Ireland (NI) using either one of two agencies (A or B) and three families were based in Italy. The Italian families all used the services of Agency B. The families included 17 children (15 boys and two girls) with ASD, that is, one family had twin boys and another family had a boy and a girl on the spectrum. The children's ages ranged from 24 months to 20 years of age. 
The average age of the children at the commencement of ABA-based interventions was 38 months, with the average length of ABA programmes being 42 months. Two families had used ABA-based interventions for much longer, that is, 17 years and six years, respectively. At the time of the study, 10 families were using ABA-based intervention and five families had stopped, feeling that their children had progressed sufficiently and no longer needed to continue with the programmes.

\section{Research tool}

The questionnaire was adapted from Keenan, Dillenburger, Doherty, Byrne and Gallagher (2007) and consisted of 20 open-ended questions. The first part focused on obtaining information about demographics, reasons for deciding to use ABA-based interventions and how they first had became aware of ABA.

The next section focused on the expectations parents had prior to using an ABA-based intervention and the impact that ABA had not just on the child but also on family life, including siblings. The third section concentrated on the procedures used in the home-based programme followed by questions about the types of support parents received prior to or throughout the ABA-based programme.

The final section of the questionnaire focused on the issues arising from the implementation of an ABA-based home programme; in particular issues relating to accessing qualified trained therapists in the local area, time considerations and impact on family life, and behavioural targets, that is, social skills, challenging behaviour, communication, gross and fine motor skills, concentration, independence and overall quality of life. A 1-5 Likert scale was used, with 1 denoting 'not achieved' and 5 meaning 'very well achieved'. 
Finally, questions looked at future directions, that is, post-intensive ABA-based programme, parents' expectations for the future of their child and recommendations to other parents of children with ASD.

\section{Research procedure}

Questionnaires were distributed using a 'gatekeeper' approach with two agencies, A and B, both of whom provided ABA-based services in Northern Ireland (NI). Agency B also provided services to families in other European countries, for example Italy. A research information sheet and consent form indicating the purpose of the study and assuring confidentiality and services continuity was read, signed and dated prior to completion of the questionnaire with an understanding that participation was entirely voluntary and that parents were free to ask questions and/or withdraw at any time.

Questionnaires were distributed via email by Agency A and B in Northern Ireland to all parents who were on the agencies database and who were currently using or who had used in the past an ABA-based intervention for their children with ASD. Out of the 15 families who participated, 10 returned completed questionnaires via email, three by surface mail and one family completed their questionnaire by telephone, due to time constraints. Data were analysed using a content analysis and thematic approach. Key words and responses were highlighted and grouped into mutually exclusive themes.

\section{Results}

Awareness of and rationale for ABA-based interventions

Most parents had learned about ABA-based interventions through their own independent search for evidence-based practices using the internet. Many parents cited reasons for their search for alternative treatments as desperation and increasingly challenging child behaviours 
with very little support from professionals. Internet searches were made using keywords such as 'effective treatments for ASD', and through reading journals and participating in online discussions ABA-based interventions were considered the basis of the most effective intervention.

Four families had not received confirmation of the diagnosis of ASD before they decided to embark on an ABA-based programme; frustration with a lack of statutory services and lengthy waiting times for diagnosis (Keenan, Dillenburger, Doherty, Byrne, \& Gallagher, 2010), even when the child showed strong traits of autism, led many parents to take matters into their own hands. Parents stated that their research on the internet indicated that ABAbased interventions appeared to provide the best possible prospects and seemed to be easily implemented in a home setting. Three parents quoted scientific evidence from a variety of sources.

All parents highlighted the lack of statutory services and support and the evidence stating that early intervention was crucial. One family was made aware of ABA through a celebrity who had used it for their own child with ASD. One family stated that ABA was recommended by their general physician. He had lent her a book by Pryor (2002) that outlined the basic principles of behaviour analysis and she began a programme of toilet training immediately. Her nearly four-year-old son was out of nappies within a week.

Talking to other parents who had used ABA-based interventions in the past was the reason for starting ABA-based interventions for many parents, with one parent highlighting that an article in a newsletter from an enthusiastic parent advocating ABA led them to choose this way of working. Another family highlighted the experience of already having one older child with ASD and not being aware of ABA at that time. A treatment and education of autistic and 
related communication handicapped children (TEACCH) approach was used with their first son. They stated:

'our son became more isolated and waiting for services that never arrived and when our second child was also displaying symptoms of ASD it led us to look for an alternative intervention; the choice being ABA'.

\section{Initial expectations}

The majority of parents highlighted a hope that ABA-based interventions would help deal with social behaviours and bring some form of normality back to family life. A better quality of life for their child and family due to reduction of uncontrollable challenging behaviours was also cited as a reason to adopt ABA-based interventions. Initially, parents did not have great expectations, with some citing a hope for even small improvements, such as 'improved eye contact', 'help with toilet training', ‘improved speech and communication'. One parent stated that 'I initially thought ABA was a play based intervention with a lot of opportunities for learning in a fun environment'. One family also stated that 'we had hopes of our child making small improvements'. Parents also hoped for improvements in their child's/children's future and the ability to catch up with their typically developing peers. Three families stated that in the beginning after reading some of the literature on early intensive behavioural intervention (EIBI), they believed there was a hope of a cure for autism, with one family stating they expected to see significant development within a few months. Some families highlighted an awareness of the time that would be involved and the inevitable financial commitment.

Impact on the child

All parents stated that ABA-based interventions had a 'positive impact on our child/children' 
with particular emphasis on reduced frustration and problem behaviours due to improved communication. ABA-based interventions impacted on their children's life in three different categories:

\section{Communication:}

'Improved eye contact, through the use of PECS (picture exchange communication system). He can now talk and can have a conversation with siblings’.

'More affectionate, can now communicate with family visitors at home'.

'More effective language skills'.

'Improved speech and language significantly, can now interact more with other people'. 'Verbal reactions have improved. He has gone from completely non-verbal to now asking questions'.

'Incredible progress in understanding and using language'.

'Significant increase in communication, he's now able to make verbal requests'.

2. Behaviour:

'She can now be understood by people outside our family'.

'More tolerant and longer attention span'.

'His reduced frustration, self-harming behaviours have stopped'.

'Improvement in concentration'.

'He now understands the consequences of behaviour'.

'We as parents now have more skills and the ability to deal with problem behaviours when they arise'.

'We have learned skills we never thought were possible'.

'He is now able to follow instructions easily and concentrate on set tasks given'.

3. Independence:

'She has learned new skills such as riding a bike and swimming'.

'Can now play, swim, and play football unaided'. 
'He's now at university studying Politics and Criminology'.

'Fully toilet trained'.

'He went from Special Education to Mainstream Education'.

'I can now take my child anywhere'.

'Able to play with siblings'.

'Helped him socially and has given him life skills and a better ability to cope with the world around him'.

'ABA has improved his academic age in Maths and English'.

'They now have the ability to learn life long skills that they were not picking up naturally like other typically developing children'.

'ABA has helped him to cope with daily life'.

\section{Impact on family life}

All parents highlighted the dramatic improvement in family life, particularly in terms of more manageable family outings and the skills they had learned in order to deal with problem behaviours in public. Families typically stated:

'we can now do things outside the home such as going to shopping centres, restaurants or on holidays, whereas before uncontrollable behaviour made these outings very stressful'.

Stress levels had been lowered and overall a better quality of life was reported by many parents, including a more positive outlook for the future of their child/children.

Most families did not receive financial support and had to pay privately for their child's/children's programme. Not surprisingly, therefore, financial burdens were noted as the 
most problematic impact; for example, one family sold their home, another remortgaged their home and a third family took out a bank loan.

The impact of having a sibling with ASD was identified with siblings asking questions such as ' why does no one come to work or play with me'. Parents expressed some feelings of guilt over the lack of time for their other children due to the intensity of the home programme for their child with ASD. However, most parents stated that they hoped, in the long term, that this would be counterbalanced as their child would be able to form better relationships and communicate with their siblings. One parent highlighted that 'more research should be dedicated to how an intensive ABA-based intervention at home affects the siblings of children with ASD'.

Two parents highlighted that their ABA-based home programme brought the family closer together with older siblings providing support and becoming involved in the programme. Two parents also stated that 'we actually felt we have now gained more time with other children when our child with ASD is in a session with their therapist'. One family stated that they now find themselves using the principles of ABA in teaching new skills to their other children. Another family also stated:

'after seeing how successful ABA was with our second child diagnosed with ASD we are now convinced how much it would've helped their older child who also has ASD and intend to also find some way for him to avail of it in the future'.

\section{Impact on parents}

The majority of parents highlighted that choosing ABA-based interventions 'involved a lot of time and commitment', for example, 'attending workshops, conferences and trying to network 
with other parents of children with ASD who were also using $A B A^{\prime}$. One family stated:

'It completely changed our views on autism in that through the use of an $A B A$ programme we now see that behaviours could be changed or strengthened and are not seen as an "insurmountable thing” that completely affects all aspects of family life'.

The same family highlighted that they became 'impatient with tea and sympathy support groups that perpetuated a victim mentality'.

Several parents mentioned the close relationships they had now formed with their children's ABA therapists due to the intensity of an ABA-based home programme and the amount of time that therapists spend in their homes. For the three Italian families the impact was slightly different in terms of language as programmes had to be translated from English into Italian and vice versa and a lot of materials had to be prepared that were not always readily available in Italy.

The personal impact on parents of receiving a diagnosis of autism was devastating in the beginning and several parents highlighted 'a grieving process' which they were going through simultaneously along with the implementation of an intensive ABA-based home programme. Two families highlighted the diagnosis of ASD as contributing to their marriage breakdown with three other parents citing depression and stress. One parent stated: 'we joined a charity, and through fighting for my son's Educational Statement needs, was able to fight in a tribunal for four others and be successful'. The same parent also became heavily involved in fundraising for specialist help and embarked on a counselling degree in order to help other parents deal with the trauma and grief of receiving a diagnosis of ASD. 


\section{Attitudes of professionals}

Some of the parents described attitudes towards ABA-based interventions by education professionals as positive:

'Mainstream Primary School was very accommodating and saw evidence of my son making great progress'.

'Classroom assistant and other teaching staff went for training in $A B A$ '.

'Consultants were welcomed into the school'.

'The Learning support Co-ordinator was in regular contact with ABA therapists'. 'Very receptive towards ABA guidance was given by the teacher to the classroom assistant'.

Only one parent mentioned support from an allied health professional: 'SALT [speech and language therapist] very supportive and stated if it were their child they would also choose an ABA-based intervention'.

However, the significant majority of parents experienced problems with education and health professionals regarding their ABA-based interventions at home:

- $\quad$ Education professionals

'They didn't like outside interference from ABA therapists'.

'No funding was made available for classroom assistants'.

'Teachers in my son's school were not very open to this type of approach'.

'Very little support from teachers in implementing the programme in class' [from two Italian parents].

'In the beginning the teacher was very apprehensive towards the programme but once 
they saw the evidence of the child's progress they were more supportive'.

'Schools not trained in how to use principles of ABA such as verbal behaviour, parents end up teaching them'.

'The Education Board were very unsupportive and I had to fight for funding'.

'My son's first school were not supportive and the Education board constantly

undermined $A B A^{\prime}$.

'Therapists were not allowed into the school on the board's request'.

- $\quad$ Health professionals

'Speech and language Therapist (SALT) said this approach was not good for children and thought parents were very naive in using this approach'.

'GP, stated "no diagnosis has been made so why start an expensive program when the child is so young?",

'Educational Psychologist was dismissive and stated that the needs of my child could only be met in a specialist unit for children with autism'.

'SALT-never acknowledged improvements made after the use of an ABA programme'. 'Professionals view it as only useful in a very restrictive way, focused heavily on the use of Discrete Trial Training'.

'When I said my child was having Speech and Language Therapy I received more positive reactions as opposed to saying my child is having $A B A^{\prime}$.

'No direct recommendation of using an ABA based intervention as a treatment for autism'.

'Community Paediatrician knew nothing of ABA and didn't believe in Early Intensive Behavioural Intervention. My son wasn't speaking at 4, but they said wait until he's 6 and then we will worry about it'.

'Very poor understanding of ABA and old fashioned thinking still prevalent in regards to treatment for ASD'. 
'I had to fight for other therapies and felt penalised for trying to help my child by using $A B A$.

'In the beginning they stopped our assistance when we stated our child was having ABA but we fought to get support and were successful [from an Italian Parent]'.

\section{Other interventions}

Six of the parents stated that they also used a gluten and casein free (GFCF) diet for their child. The majority of parents used speech and language therapy and occupational therapy, although very intermittently with minimal hours offered. One family also used sensory integration and cranial sacral therapy. Another family used a charity that specifically promoted social and independent living skills but did not specify the intervention methodology. One Italian family stated that 'due to a lack of knowledge about $A B A, a$ TEACCH programme had been recommended before beginning an ABA based programme'.

\section{Effectiveness of ABA-based intervention}

The vast majority of parents considered ABA-based intervention as 'very effective' or 'effective' (Table 1). Some parents focused on certain behaviour categories for improvement more than others. For example, two families considered gross and fine motor skills as 'Not Applicable' (NA) because these were not an issue for their child. One family stated: 'it was too early to tell. We have only started the programme one year ago when our twin boys were seven years old'. Another family who scored 2 on social skills also stated that 'due to our child's profound autism parts of the programme were too difficult'; however the same parent gave a 5 on communication and a 4 for both behaviour and interaction. One family stated that their focus from the beginning was solely on improving 'social skills and communication'. Another family who also scored 2 on social skills and overall quality of life had only been using an ABA programme for four months. 


\section{Financial assistance}

In response to the question about financial assistance for an ABA-based intervention, the majority of parents stated that 'we received no financial assistance'. One family stated that they received Disability Living Allowance (DLA) which covered some costs and another two families received some financial assistance from two different charities. Two families received small grants from education boards for a period of one year. One family successfully took their education board to Court; that is, the board was ordered to pay for part of the programme. Four families stated that 'we fundraised ourselves to pay for $A B A$ ', one family stated that 'we had to sell our home' with another family highlighting that 'we had to remortgage our home to pay for the programme'. One Italian family stated that 'after much fighting we now receive 15 hours a week of Government funding to help pay for therapists'.

\section{Changes in expectations}

In response to the question about changes in expectations, the majority of parents stated that 'our expectations changed'. Two families no longer believed in 'curing their child' and highlighted that 'ABA doesn't advertise itself as such'. Most parents highlighted that they now put an emphasis on using an ABA-based intervention to deal with challenging behaviours and for social skills development. Several families stated that 'what we found useful in using $A B A$ is that throughout the programme it could be adjusted and tailored to the child's individual needs'.

Four families stated that 'we became more convinced of the value of ABA as time progressed' with one stating that 'the more we see our child improve the more hope we have for the future and are very grateful to ABA for that'. Many parents highlighted that the range of situations in which they now saw ABA working had 'widened from the beginning', using examples from 
the home environment to schools and public places. One parent with both a boy and a girl with ASD stated that they saw how each child responded individually to an ABA-based programme with her daughter making more gains in certain areas such as social skills; however her son gained more improvement in terms of challenging behaviour. One family also stated:

'you naively believe in the beginning that it will solve all your problems as you're so desperate; but what you see is that it unlocks your child in that the focus is no longer on their autistic traits, with their strengths being brought more to the surface'.

Another family now saw that ABA 'is not a quick fix' and, having thought that it would focus solely on behaviour and social skills, they now expressed an ability to see a variety of skills that can be worked on through the use of ABA-based interventions.

\section{Recommendations for other parents}

Parents gave the following responses when asked if they would recommend the use of ABAbased interventions to other parents:

'Yes, the more you put in, the more you get out'.

'Yes, without hesitation but you need to be aware of the financial and time commitment'.

'Without a doubt, it has changed all our lives for the better'.

'Highly recommend this type of intervention, the gains my children made far outweigh the negatives'.

'Yes, of course! Yes if you can afford it and have a strong support network'.

'Yes very much so but it requires a big commitment both in time and financially'.

'Yes but you need to be realistic in the beginning, it is not a cure'. 
'Very much, nearly all issues or behaviours can be addressed through an ABA approach'.

'Yes, although it's not the easiest option, it's worth the effort'.

'Yes, wholeheartedly'.

'Yes, but don't expect dramatic change within the short term'.

'Always, it's the best intervention as it's based on a science and all the behaviours are followed by data and the use of $A B C$ '.

\section{Future expectations}

When parents were asked about the hopes and concerns for the future for their child/children, the majority stated 'the ability to have the skills to live as independently as possible'. Many families commented that:

'we hope that choosing an ABA-based intervention provides our children with skills for life which they can use to integrate into a social world and have genuine relationships where they are seen for their strengths and accepted for who they are'.

Three families stated that they worry about the future like all parents but that they were concentrating on improving what they can in the here and now. Another family reflected:

'raising children is difficult anyway but with the extra worry we have for a child with ASD, one day at a time is the best outlook for our family as looking too far ahead can be a frightening picture’.

One parent said that they worry about problem behaviours in the teenage years and the inability to live an independent life. Another family stated that 'we hoped that by starting an 
ABA-based programme with our child so young would provide him with the skills needed to fit in with his typically developing peers'. The same family highlighted that 'we can't take away our child's autism, but we can help to make his behaviours less noticeable so that he can lead a more normal life in the future'.

\section{Additional comments}

Parents were asked to give any other comments or raise any important additional questions. Two families highlighted the criticism that both they and their service provider received due to the expense of the privately funded programmes. However they stated:

'we would still do it the same way as we both have full time jobs and feel that we cannot implement a home based ABA-programme without additional help ... yes it is expensive but we felt that due to a severe lack of statutory services we were left with little choice’.

Three families stated that 'we wished that professionals particularly in Health and Social Care would be more objective and make decisions based on evidence and not outdated theories'. One family also added that 'ABA should be made a central strategy for children and adults not just with autism but with a range of disabilities and challenges'.

Several families highlighted lack of funding and public services allocated towards ABA with two families stating 'that we would like to be able to pay for more ABA treatment but cannot afford it'. The majority of parents finally highlighted that 'more understanding is needed particularly in Education with an emphasis on training in the principles of ABA'. All families highlighted the 'invaluable support that they received from both, Agencies A and B, in Northern Ireland that provided services and training to them'. Another family also stated: 
'we wished there was more funding for $A B A$ as in the long term it would save the Health Service in Northern Ireland money if they helped children with ASD when they were younger'.

\section{Discussion}

Parents' experiences of using ABA-based interventions for their child/children with ASD were reported. Results showed that ABA-based interventions had a significant positive impact not only on the lives of the child, in particular in areas of communication, challenging behaviours and independence, but also on the family as a whole and their overall quality of life. The study showed a high level of parental satisfaction with using ABA-based interventions and confirmed Keenan et al.’s (2007) results that parents support the need for wider use and public support of ABA and that statutory services were severely lacking with many professionals unwilling to endorse it despite its empirical evidence. What was clearly evident from this study was that six years after Keenan et al.'s study was published, 'effective science-based intervention in Northern Ireland still remains the responsibility of parents and voluntary bodies and is carried out mainly by parents in their own homes, rather than being embraced by statutory agencies’ (Keenan et al, 2007, p. 123).

Families and children with ASD need and deserve the best treatment that is evidence-based (Morris, 2009). Yet many parents in the study reported here were dissuaded from using ABAbased interventions by professionals who evidently were not as well informed as parents (Dillenburger, Keenan, Doherty, Byrne \& Gallagher, 2010). The expense of privately funded home-based ABA interventions was a problem. However, if publicly funded educational services were to offer high-quality ABA-based interventions, parents would not have to resort again to the extreme measures highlighted in this study to ensure that their children receive appropriate evidence-based education. 
Knapp, Romeo, \& Beecham, (2009) showed the enormous economic costs of supporting children and adults with ASD who do not receive EIBI and consequently need intensive lifelong care. Parents in Europe are in the vulnerable situation where very little early intensive behavioural intervention is offered. Parents need to be supported by professionals who will help them to make informed decisions that are objective and based on scientific evidence. There is a need for parents to 'know what not to pursue as much as what to pursue' (Ridge \& Guerin, 2011, p. 247).

Parents also highlighted the responsibility of the education system to embrace the scientific methods of ABA-based interventions and not just in the treatment of children with ASD. Policies like ‘Every Child Matters’ and ‘Inclusion’ are supposed to be at the heart of educational legislation and, as Keenan and Dillenburger (2009, p. 10) argue, methods based on science should be applied in the education of children with autism. The scientific methods used in ABA recognise that each child is different and therefore each child's potential is maximised by assessing the effectiveness of how and what is taught. Keenan et al. (2007, p. 24) argue that for a student to be successful or to bring out the best in them is 'to examine whether the delivery of the curriculum incorporates fundamental principles of behaviour'.

The purpose or goal of the curriculum is to bring the person to the point where they have the skills and confidence to live in an ever-changing and demanding world; concerns that parents have expressed in this study show that this is not the case for their children with ASD in the publicly funded education system. If children are grouped according to ability or labels the potential for change can be overlooked (Hart, Drummond \& McIntyre, 2007). The philosophy that ASD is a lifelong disability means that a 'prosthetic environment' (Jordan, Jones \& Murray, 1998, p. 79) rather than skills development is the focus of intervention. Parents in this 
study evidenced their disaffection with this approach.

There is an urgent need to re-educate professionals regarding the principles of ABA. This study highlighted that parents are often better educated about the principles of ABA than education or health and social care professionals. Only when professionals understand and become informed about ABA will accurate recommendations be made in government reports, thus facilitating more funding and enabling more families to access better services for their children.

\section{References}

Baer, D. M., Wolf, M. M. \& Risley, T. R. (1968) 'Some current dimensions of applied behavior analysis’, Journal of Applied Behavior Analysis, 1, 91-97.

Chiesa, M. (2005) 'ABA is not a therapy for autism’, in M. Keenan, M. Hendersron, K. P. Kerr \& K. Dillenberger (eds) Applied behaviour analysis and autism: building a future together. London: Jessica Kingsley.

Dillenburger, K. (2011) 'The emperor’s new clothes: eclecticism in autism treatment', Research in Autism Spectrum Disorders, 5, 1119-1128.

Dillenburger, K., Keenan, M., Doherty, A., Byrne, J. \& Gallagher, S. (2010) 'Living with children diagnosed with autism spectrum disorder: parental and professional views', British Journal of Special Education, 37, 13-23.

Eikeseth, S., Smith, T., Jahr, E. \& Eldevik, S. (2002) 'Intensive behavioral treatment at school for 4- to 7-year-old children with autism: a 1-year comparison controlled study’, Behavior Modification, 2, 49-68.

Hart, S., Drummond, M. J. \& McIntyre, D. (2007) 'Learning without limits: constructing pedagogy free from determinist beliefs about ability', in L. Florian (ed.), The Sage Handbook of Special Education. London: Sage. 
Howard, J. S., Sparkman, C. R., Cohen, H. G., Green, G. \& Stanislaw, H. (2005). A comparison of intensive behaviour analytic and eclectic treatments for young children with autism', Research in Developmental Disabilities, 26, 359-383.

Jordon, R., Jones, G. \& Murray, D. (1998) ‘Educational interventions for children with autism: a literature review of recent and current research, Final report to the DfEE. Birmingham: University of Birmingham, School of Education.

Keenan, M. \& Dillenburger, K. (2009) 'When all you have is a hammer ... RCTs and hegemony in science', Research in Autism Spectrum Disorders, 5, 1-13.

Keenan, M., Dillenburger, K., Doherty, A., Byrne, T. \& Gallagher, S. (2007) Meeting the needs of families of children diagnosed with autistic spectrum disorder [online at www.peatni.org/uploads/27122007215234_AUTISMREPORT.pdf].

Keenan, M., Dillenburger, K., Doherty, A., Byrne, J. \& Gallagher, S. (2010) 'Experiences of parents during diagnosis and forward planning for children with autism spectrum disorder’, Journal of Applied Research in Intellectual Disabilities, 23, 390-397.

Keenan, M., Dillenburger, K., Moderato, P. \& Röttgers, H. R. (2010) ‘Science for sale in a free market economy: but at what price? ABA and the treatment of autism in Europe', Behavior and Social Issues, 19, 124-141.

Knapp, M., Romeo, R. \& Beecham, J. (2009) 'Economic cost of autism in the UK', Autism, 13, 317-333.

Lovaas, O. I. (1987) 'Behavioral treatment and normal educational and intellectual functioning in young autistic children', Journal of Consulting and Clinical Psychology, 55, 3-9.

Matson, J. L., Benavidez, D. A., Stabinsky Compton, L., Paclawskyj, T. \& Baglio, C. (1996) 'Behavioral treatment of autistic persons: a review of research from 1980 to the present', Research in Developmental Disabilities, 17, 433-465.

McConkey, R., Kelly, G. \& Cassidy, A. (2007) An evaluation of the need and early 
intervention support for children (aged 2-4 years) with an autistic spectrum disorder in Northern Ireland, Department of Education, No. 44. Belfast: Statistics \& Research Agency Northern Ireland.

Morris, E. K. (2009) 'A case study in the misrepresentation of applied behavior analysis in autism: the Gernsbacher lectures’, The Behavior Analyst, 32, 205-240.

National Autism Center (2009) National Standards Project, National Autism Center, Massachusetts [online at www.nationalautismcenter.org/pdf/NAC\%20Findings\%20\&\%20Conclusions.pdf].

Pryor, K. (2002) Don’t shoot the dog. New York: Bantam Books.

Ridge, K. \& Guerin, S. (2011) 'Irish clinicians’ views of interventions for children with autistic spectrum disorders', The National Autistic Society, 15, 239-252.

Ruane, C. (2009) Answer to ministerial question from George Robinson, Department of Education, letter dated 17 June.

Sallows, G. O. \& Graupner, T.D. (2005) 'Wisconsin Early Autism Project (Madison) intensive behavioral treatment for children with autism: four-year outcome and predictors’, American Journal on Mental Retardation, 110, 417-438.

Task Group on Autism (2002) The education of children and young people with autistic spectrum disorders. Report of Task Group on Autism. Belfast: Department of Education [online at www.deni.gov.uk/index/7- special_educational_needs_pg/special_educational_needs__reports_and_publications-newpage-2/special_educational_needs__reports_and_publications-newpage-4.htm].

Weiss, M. J. (1999) 'Differential rates of skill acquisition and outcomes of early intensive behavioral intervention for autism', Behavioral Interventions, 14, 3-22.

Wolf, M. M., Risely, T. R. \& Mees, H. (1964) ‘Application of operant conditioning procedures to the behavioural problems of an autistic child', Behaviour Research and 
Therapy, 1, 305-312.

Research reported here was conducted in part-fulfillment of the MScASD at Queen's University Belfast by the first author under the supervision of the second author.

Address for correspondence:

Karola Dillenburger

Queen’s University Belfast - Education

69 University Street

Belfast Down BT71HL

UK

Email: k.dillenburger@qub.ac.uk

Article submitted: April 2013

Accepted for publication: August 2013 
Table 1: Parental scores for effectiveness of ABA-based intervention on specific target behaviours for their child/ren

\begin{tabular}{|l|l|l|l|l|l|}
\hline Target behaviour & $\begin{array}{l}\mathbf{5} \text { Very } \\
\text { effective }\end{array}$ & $\mathbf{4}$ & $\mathbf{3}$ & $\mathbf{2}$ & $\begin{array}{l}\text { 1 Least } \\
\text { effective }\end{array}$ \\
\hline Social skills & $3^{*}$ & 4 & 6 & 3 & \\
\hline Behaviour & 5 & 6 & 4 & & 1 \\
\hline Communication & 9 & 6 & 1 & 1 & \\
\hline Gross and fine motor skills & 2 & 9 & 4 & & 1 \\
\hline Concentration & 4 & 3 & 6 & 1 & \\
\hline Interaction & & 8 & 7 & 1 & \\
\hline Independence & 1 & 6 & 7 & 1 & 1 \\
\hline Overall quality of life & 4 & 9 & & 1 & \\
\hline
\end{tabular}

*number of responses. 